\title{
La coexistencia contenciosa: la ausencia de discusiones
}

$\mathrm{F}_{\text {n la masacre del Alto Naya hay una particularidad que marca cier- }}$ recordar que tres semanas después de la acción paramilitar del bloque Calima en abril de 2001, los operativos de la Infantería de Marina permitieron la captura de setenta paramilitares que, posteriormente, fueron judicializados como autores materiales de la masacre. La justicia colombiana, poco menos de cuatro años después, condenó a los imputados a purgar la máxima condenada contemplada en la legislación penal, 40 años de prisión, por los delitos de homicidio con fines terroristas, desplazamiento forzado y concierto para delinquir. Revisando el contenido de la sentencia, un primer aspecto que llama la atención es que, exceptuando el caso de algunos imputados, casi todos los paramilitares negaron siempre cualquier tipo de responsabilidad en la masacre, incluyendo algunos que, aunque aceptaron pertenecer al grupo paramilitar y haber participado en la acción del 10, 11 y 12 de abril, rechazaron participación alguna en los asesinatos, desapariciones, desplazamiento y demás violaciones perpetradas. Dado que entre los paramilitares que decidieron confesar no hubo delación frente a otros compañeros (todos recluidos en un mismo pabellón de la cárcel del municipio vallecaucano de Palmira), fueron los argumentos y las evidencias presentadas por la Fiscalía 18 de Derechos Humanos las que configuraron los cargos 
para la imputación y para la condena. En pocas palabras, la revisión de la sentencia permite decir que hubo justicia pero no precisamente verdad $^{109}$. La sentencia condenatoria se produjo en febrero de 2005 y fue proferida por el juzgado primero penal del circuito especializado de Popayán, un par de meses antes de que entrara en vigencia la Ley 975 o Ley de Justicia y Paz, que traía, como principal promesa de valor, una pena máxima de presidio de ocho años, sobre la base de garantizar, ante todo, la verdad a las víctimas. Ello implicaba para los hombres del bloque Calima encarar un nuevo proceso judicial. No obstante, los vacíos y las inconsistencias de la norma no permitieron que los hombres que previamente habían sido condenados por la masacre del Alto Naya pudieran ser postulados a Justicia y Paz. Solo hasta el año 2010, cincuenta de ellos entraron a formar parte del proceso ${ }^{110}$. $\mathrm{Y}$ a partir de ese momento el escenario de Justicia y Paz adquiere un cariz diferente respecto a otros procesos contra bloques paramilitares, pues los hombres que participaron en las acciones en la región del Alto Naya llevan poco más de diez años de presidio, puesto que su captura se produjo en mayo de 2001. Para estos hombres, aportar al principio de "verdad" implicaba, en términos jurídicos, una rebaja de pena que prácticamente significaría su excarcelación ${ }^{111}$. Sobre esa base,

109 Los sobrevivientes de la masacre expresan en las conversaciones que no se sienten conformes a pesar de lo ejemplar que puede resultar la condena.

110 El bloque Calima se desmovilizó oficialmente en diciembre de 2004, cuando 564 hombres comandados por Éver Veloza García entregaron sus armas. Según la Ley de Justicia y Paz, era el comandante de cada uno de los bloques desmovilizados quien tenía la potestad de efectuar la postulación de los hombres que tenía a su cargo. Veloza García hizo una primera postulación de 21 nombres, de los cuales solo 13 pudieron rendir versión libre ante los fiscales de Justicia y Paz. Los paramilitares que fueron capturados en 2001 quedaron excluidos del proceso porque simplemente nadie los postuló. Este vacío jurídico fue subsanado en 2008 mediante la expedición del Decreto 4719, que permitió que los paramilitares que se hallaban presos pudiesen postularse de manera individual. Sobre esa base, recién en 2010, alrededor de cincuenta hombres se vincularon a Justicia y Paz.

111 En la actualidad hay una compleja discusión jurídica al respecto, pues el abogado defensor solicitó a la Sala de Justicia y Paz del Tribunal Superior de Bogotá la excarcelación de los postulados que fueron capturados en 2001, sobre la base 
las confesiones de los paramilitares del bloque Calima han resultado "iluminadoras" para reconstruir lo acontecido en abril de 2001, pero también para reconstruir el cuadro de acciones del bloque Calima en tres departamentos del suroccidente del país, sin que ello indique que las confesiones dejen de responder a unos libretos previamente preparados. Pero ¿cómo son leídos esos testimonios por los representantes de las comunidades del Alto Naya? ¿Cuáles son las impresiones que median en ellos cada vez que salen de una audiencia que, además de extenderse por días, se desarrolla en largas y extenuantes jornadas? ¿Cuál es la trascendencia social y política que tienen las confesiones de los perpetradores en un horizonte más amplio?

Para abordar los anteriores cuestionamientos, conviene retomar algunas de las consignas que trabaja Leigh Payne (2009) en torno al poder político que adquieren los relatos confesionales en escenarios que, como el colombiano, apuntan a un proceso de transición política y social. La primera idea es que las confesiones no ajustan cuentas con el pasado y, por el contrario, resultan perturbadoras tanto en el plano individual como en el colectivo en cuanto que no necesariamente revelan la "verdad". Las confesiones, entonces, responden más a libretos en los que subyacen intereses de distinta índole, dentro de los cuales se destacan justificaciones y explicaciones cargadas de revelaciones, silencios, omisiones y olvidos, que configuran unas versiones sobre el pasado usualmente discutidas, controvertidas o rechazadas por unas audiencias integradas por víctimas, sobrevivientes y activistas de derechos humanos. El conflicto aparece cuando los actores discuten sobre los sentidos atribuidos a lo sucedido y compiten por la legitimidad de estos para que las interpretaciones se instalen en la agenda política y el debate público. Como señala Payne (2009), el problema está en unas confesiones que tienden a justificar los actos perpetrados eludiendo

de la contribución a la "verdad" y "esclarecimiento de los hechos" a través de las versiones libres rendidas hasta la fecha. No obstante, los magistrados han negado la solicitud acogiéndose a lo dicho por la Corte Suprema de Justicia respecto a que la pena se comienza a ejecutar desde el momento en que se produce la postulación. En consecuencia, los postulados tendría que purgar todavía alrededor de cinco años más de cárcel. 
o minimizando cualquier tipo de responsabilidad personal, sin que medie un acto de disculpa, lo que propicia mayores tensiones sobre el pasado en vez de disminuirlas. Consciente de que las confesiones en vez de promover la discusión y la reconciliación, lo cual atenta contra la democracia misma, Payne le apuesta a un ejercicio de coexistencia contenciosa en el que la rivalidad sobre las ideas, así como el conflicto que se produce sobre los valores y las metas, caractericen las discusiones. En consecuencia, le apuesta a la coexistencia contenciosa, pues

estimula las prácticas democráticas al promover la participación política, la polémica y la rivalidad [...], ofrece una comprensión más realista de las prácticas dialógicas en las democracias, así como una mejor alternativa para los proceso de reconciliación que reprimen el debate público. (Payne, 2009, p. 3)

Para Payne las confesiones de los perpetradores permiten penetrar en la coexistencia contenciosa en la medida en que los relatos y sus sentidos provocan un profundo conflicto político. Su promoción y su discusión pública es importante, sin que esto implique una amenaza para la estabilidad democrática. Ahora bien, esta politóloga norteamericana no desconoce que el debate implica que la confesión se desarrolle en un contexto amplio que precisamente propicie la coexistencia contenciosa. Se configura, entonces, lo que ella denomina como un drama político en el que los perpetradores y las audiencias compiten en un escenario en el cual hay un actor que narra la historia del pasado, ofrece en esa narración una serie de argumentos, esa narración implica unas actuaciones que se despliegan en un escenario. Las audiencias, conscientes del poder político en juego, usan las confesiones para asumir posiciones particulares. El trabajo empírico de Payne la lleva a identificar unas tipologías de representación confesional, a partir de las cuales se puede desplegar el debate de coexistencia contencio$s a$ : remordimiento y heroísmo (asociados comúnmente a la reconciliación); sadismo y negación (que socavan la democracia en vez de fomentarla); silencio, ficción, mentiras, amnesia y traición-delación. En otras palabras, el trabajo de Payne (2009) se propone analizar el impacto que los testimonios de los perpetradores tienen en la consolidación de la democracia. Ese propósito discute con las dos opciones 
extremas respecto a la divulgación de las confesiones de los perpetradores: en una orilla, los que tienden a evitarlos, limitarlos o silenciarlos, por considerar que esos testimonios lo que hacen es reabrir heridas, revictimizando a los sobrevivientes y a sus familias; y en la otra orilla están aquellos que tienden a otorgar poderes terapéuticos a las confesiones en la medida en que las revelaciones permiten el conocimiento pleno de la verdad, lo que procura tranquilidad personal y reconciliación colectiva (Uprimny, Saffon, Botero y Esteban, 2006, p. 17). De ahí que los argumentos de Payne procuren reconocer que los testimonios confesionales en procesos jurídicos transicionales no garantizan la ilusión de un consenso político reconciliatorio. Por el contrario, es muy probable que en contextos marcados por una violación sistemática de los derechos humanos, las versiones sobre el pasado sean irreconciliables y que las disputas se extiendan por largo tiempo. Lo anterior no implica que los testimonios de los perpetradores deban limitarse o silenciarse. Su promoción, en un horizonte dialógico y conflictivo, debe buscar un debate contencioso que estimule la participación deliberativa y crítica, lo cual tendrá efectos positivos para la construcción y el fortalecimiento de la democracia (2009, pp. 36-42).

Los anteriores planteamientos resultan apropiados para comprender la percepción que tienen los representantes de las víctimas y los sobrevivientes del Alto Naya, sobre todo cuando evocan lo sucedido en el proceso adelantando en la justicia ordinaria y lo contrastan con lo acontecido en Justicia y Paz, pues, en palabras de Elvira: "La mayoría de ellos buscó evadir su responsabilidad en todo lo que hicieron en el Alto Naya, incluyendo la incursión del mes de abril de 2001" (notas de campo, septiembre de 2013).

Su malestar es justificado cuando se revisan las declaraciones de los paramilitares del bloque Calima durante la etapa investigativa y procesal. Los testimonios responden a un libreto en el que subyace una estructura que, más allá de las variaciones entre una versión y otra, configuran, grosso modo, los siguientes sentidos:

Los hombres aceptan ser integrantes de las Autodefensas, señalando que su vinculación se produjo por motivos económicos. Coinciden en afirmar que se les ofreció un salario de trescientos mil pesos (alrededor de 150 dólares) mensuales. La mayoría también coincide en sostener 
que su vinculación al grupo fue relativamente reciente. Solo unos pocos reconocieron que se vincularon al paramilitarismo con la intención de combatir a las Farc-EP, pues fueron víctimas del grupo insurgente.

A pesar de reconocer su vinculación al grupo paramilitar, también hubo consenso respecto a negar la participación en la acción en el Alto Naya, argumentando que se movilizaban en grupos que iban a la zaga de los hombres que lideraban la acción. Esta versión es desvirtuada por el testimonio que ofrece Rubén Darío Rovira Benítez, que fue el primero en relatar la forma como se produjo la incursión. En su versión, queda claro que al Alto Naya ingresan 250 hombres, pero que el grupo, luego, se divide en dos: 130 continúan con la incursión por el camino real que conduce a la zona alta y 120 se dirigen a otro lugar del departamento del Cauca. Menciona que hubo enfrentamientos con la insurgencia y que buena parte del camino se hizo de la mano de un miliciano del ELN que fue capturado y obligado a señalar a las personas insurgentes o colaboradores de la insurgencia. En ese sentido, niega que en la incursión se hayan asesinado a civiles, pues todos fueron insurgentes. También menciona que las personas civiles muertas fueron masacradas por las Farc-EP y el ELN.

A partir del testimonio de Rovira Benítez, el libreto sostiene la versión de que los muertos en el Naya fueron "dados de baja” y "eliminados" por ser "guerrilleros", y que los civiles muertos fueron masacrados por los dos grupos insurgentes con la intención de inculpar a las AUC. En la manera como se verbaliza y se adjetiva en los relatos, se utilizan palabras eufemísticas en torno a la ejecución de los pobladores. Esa versión se mantiene hasta el final del proceso ${ }^{112}$, y se amplía con explicaciones como que nunca utilizaron motosierras para asesinar a nadie.

El libreto confesional es reforzado con la versión de que el grupo paramilitar capturó a un miliciano del ELN, mencionado con el alias de Peligro, y que fue este quien señaló a las personas que posteriormente

112 Incluso es sostenida por los pocos paramilitares que decidieron acogerse a sentencia anticipada como herramienta jurídica que garantiza en la legislación penal colombiana una rebaja hasta de una cuarta parte de la pena cuando se aceptan los cargos imputados por la Fiscalía. 
fueron asesinadas. Los testimonios, entonces, hablan de 12 a 18 personas "ejecutadas" a lo largo del recorrido. La versión no varía a pesar de lo dicho en indagatoria por José Antonio Morales Galindo, quien si bien negó su participación en las muertes, aceptó que se ingresó a la región con una lista de personas. Según el testimonio, en los retenes que montó el grupo paramilitar se detenía a los pobladores y se les preguntaba nombre y número de identificación; si aparecían en la lista, eran ejecutados de un tiro, pero podían salvarse si colaboraban dando información sobre los insurgentes. Este testimonio es significativo porque confirma la versión dada por Éver Veloza García, comandante del bloque, respecto a que toda operación se adelantaba con un trabajo previo de inteligencia de la que se obtenía una lista de personas, muchas de ellas proporcionadas por las fuerzas militares en un marco colaborativo. No obstante, en este primer proceso no hay testimonios que inculpen a las fuerzas militares, lo cual puede explicarse en la medida en que los hombres capturados en abril de 2001 fueron en su mayoría mandos medios y soldados rasos con información limitada.

Finalmente, hay casos que, para los representantes del Alto Naya, son indignantes, como el de Jair Alexander Muñoz Borja, quien negó cualquier tipo de participación en la masacre, y cualquier tipo de vinculación con el paramilitarismo, a pesar de las evidencias presentadas por la Fiscalía. Una de ellas era un video en el que Muñoz Borja aparece organizando escuadras paramilitares en el Valle del Cauca en 1999.

Un panorama distinto aparece cuando los paramilitares condenados deciden acogerse a la Ley 975 (2005). Las versiones responden a un nuevo libreto que, sin duda alguna, resulta más iluminador para comprender lo acontecido en el Naya, así como lo sucedido en un lapso de cuatro años en los departamentos del Valle, el Cauca y el Huila por el bloque Calima. En ese contexto, no sería errado afirmar que los testimonios confesionales son "esclarecedores" para unas instituciones públicas, como la Fiscalía como ente investigador, que han logrado reconstruir las actuaciones del bloque paramilitar. No obstante, para los sobrevivientes, las familias de las víctimas y los líderes de la región del Naya, los testimonios de los perpetradores siguen siendo perturbadores, puesto que el nuevo libreto sigue minimizando las responsabilidades particulares en los hechos victimizantes y, en los casos en que 
los perpetradores han expresado arrepentimiento, disculpas y hasta perdón por sus actos, entre los asistentes a las audiencias se expresa incredulidad ante la puesta en escena en las audiencias.

Respecto al primer aspecto, aunque hay un reconocimiento de las atrocidades perpetradas, en algunos casos persisten las justificaciones que minimizan las responsabilidades o que atribuyen esas responsabilidades a "otros". También está el caso de los paramilitares que no fueron capturados ni se entregaron a las autoridades en la desmovilización de 2004. Finalmente, también están las argumentaciones que buscaron menguar su responsabilidad diciendo que obedecían órdenes de los superiores ${ }^{113}$. De cualquier modo, la perturbación de las víctimas y los sobrevivientes está en que no reconocieron su responsabilidad moral, indistintamente de la participación en las acciones. Como lo sostuvo Elvira: "Más que justificaciones lo que esperamos es que se acepte que lo que hicieron estuvo mal" (notas de campo, septiembre de 2013).

Se esperaría que las confesiones fueran menos inquietantes cuando los perpetradores piden perdón por lo que hicieron, aceptando que sus actos causaron "un daño irreparable" del cual se arrepienten. No obstante, esos testimonios de arrepentimiento no resultan creíbles para los asistentes porque los perpetradores no están presentes físicamente en el estrado judicial, sino que los testimonios se transmiten a través de una pantalla que, mediante videoconferencia, conecta a los perpetradores desde su lugar de reclusión con los asistentes en el estrado judicial, incluyendo a los jueces.

¿Qué implica que las confesiones de los perpetradores estén mediadas por esa prótesis teletecnológica (Derrida y Stiegler, 1998, p. 40)? La mediatización del testimonio del perpetrador transcurre en una doble puesta en escena: hay una primera puesta en escena que se va

113 Sobre el particular es preciso no perder de vista que el argumento de estar cumpliendo órdenes de mandos superiores no puede enmarcarse en el siempre álgido debate de la obediencia, pues se trata de un grupo irregular que perpetra una serie de acciones violatorias a los derechos humanos y al derecho internacional humanitario contra la población civil. Se comprende que sus actuaciones son, desde un principio, criminales, más allá del argumento de considerar a esa población civil objetivo militar por ser catalogada como auxiliadora de la insurgencia. 
construyendo cuando el perpetrador moldea su confesión según un libreto que será representado en el escenario judicial; pero a esa puesta en escena se yuxtapone una segunda puesta en escena cuando el libreto, además, es representado ante una cámara de televisión. El perpetrador no le habla a unos asistentes en el mismo espacio. Sus palabras se dirigen a una cámara que, si bien registra imagen, voz, tonalidades, movimientos y gestos, también establece una distancia física - una actuavirtualidad en palabras de Derrida- respecto a otros: los asistentes al estrado judicial, que observan a través de una pantalla lo que se dice como espectadores televidentes ${ }^{114}$. Las dos puestas en escena tienen en común el apostar por una narración verosímil, entendiendo que este es un elemento sustancial en el despliegue de todo relato. Pero el hecho de que las confesiones se mediaticen establece un nuevo marco de interpretación en el que la verosimilitud de las confesiones se desvanece por las distancias que esa prótesis teletecnológica configura en el escenario judicial. Los asistentes, entonces, reconocen con claridad a los perpetradores como actores que interpretan o representan un rol. En palabras de muchos asistentes a las audiencias, incluso los que participan en ellas aunque no sean víctimas o sobrevivientes, la sinceridad y la veracidad de las palabras pierden su fuerza enunciativa cuando no se tiene la oportunidad de mirar de frente al perpetrador, de poder detallar los gestos que hace mientras habla, cómo mueve las manos, cuáles son sus reacciones a ciertas situaciones que se producen durante la audiencia, incluyendo aquellas en las que no están declarando. Ello se mantiene en las situaciones en que las confesiones mediatizadas resultan verosímiles. Elvira, por ejemplo, ha tenido

114 No se debe confundir esta situación particular que caracteriza a Justicia y Paz con el hecho de que en la mayoría de los juicios las confesiones y los testimonios sean registrados a través de medios audiovisuales que quedan como archivo. Sin duda alguna, en esos casos el imputado sabe que lo están grabando, pero ello no implica que hable o se dirija a las cámaras. Su mirada, su voz, sus actos de comunicación usualmente se dirigen a los otros actores en la escena judicial. De igual forma, el registro audiovisual es más preciso porque, precisamente, registra detalles a los cuales se puede volver una y otra vez para analizarlos, pero eso no es lo que buscan las víctimas y los sobrevivientes cuando asisten a un juicio. 
la oportunidad de escuchar en varias oportunidades las declaraciones de Éver Veloza García, quien rinde sus versiones libres en una cárcel del estado de Manhattan, Estados Unidos. Elvira, tras escuchar lo dicho por el antiguo jefe del bloque Calima, le cree a las revelaciones sobre los vínculos de los paramilitares con miembros de la fuerza pública, pero es totalmente escéptica cuando Veloza García sostiene que se arrepiente de lo que hizo. Su escepticismo es producto del distanciamiento que provoca el escuchar sus palabras en una pantalla que generan en Elvira cierta sensación de impotencia porque no puede encarar al perpetrador: "qué importa si es sincero cuando ellos piden perdón o dicen estar arrepentidos por lo que hicieron si no podemos verlos a los ojos..." (notas de campo, abril de 2012) ) $^{115}$.

A lo anterior hay que agregarle que las revelaciones de los perpetradores también son perturbadoras porque abren nuevos interrogantes, inquietudes y discusiones. Las más significativas están relacionadas con las "verdades" sostenidas por los postulados en las que se detallan los vínculos que el grupo paramilitar estableció con distintos actores de los ámbitos regional y local, que explicarían los factores políticos, sociales y económicos de las acciones victimizantes ${ }^{116}$. Se re-

115 Para ejemplificar la sensación de impotencia que experimenta Elvira, quiero referir una situación ocurrida pocos meses después de conocerla, cuando asistimos a la proyección de Impunity (2011), un documental realizado por los periodistas colombianos Hollman Morris y Juan José Lozano sobre la guerra en Colombia. Nos sentamos en la sala de proyección abarrotada de estudiantes. En uno de los apartados del documental aparece Veloza García. Elvira reaccionó a lo dicho por el paramilitar y comenzó a discutir en medio de la oscuridad. Tuvimos que salirnos de la sala porque ella quería hablar. Ese día me contó por primera vez cómo se salvó de ser asesinada por los paramilitares en la masacre de abril de 2001.

116 La Fiscalía de Justicia y Paz estableció un protocolo que distingue entre los hechos enunciados y las confesiones. La primera categoría responde a los recuerdos de los paramilitares en relatos cargados de olvidos, silencios y omisiones respecto a las acciones perpetradas; los hechos enunciados se desarrollan en el marco de lo que la ley define como versiones libres. Las confesiones, en principio, son actos de aceptación de los delitos imputados, usualmente con las víctimas presentes, luego de que la Fiscalía ha demostrado la responsabilidad de los postulados en los hechos victimizantes. 
conoce, entonces, la importancia de la investigación judicial que permita la reconstrucción de una acción paramilitar que produjo una masacre, pero también se observan los vacíos para ofrecer elementos que expliquen las acciones paramilitares en una región geopolítica y geoeconómicamente estratégica. Para los representantes del Naya, las acciones del bloque Calima en la región no quedan totalmente explicadas cuando se adopta la versión de la "venganza" por los secuestros de la iglesia de La María y del kilómetro 18, puesto que esa explicación se "oficializa” y oculta otros factores políticos y económicos más relevantes. De ahí que su perturbación esté ligada a una percepción de "injusticia" respecto a las personas — militares, políticos o comerciantes- que, según los testimonios confesionales, estuvieron vinculadas con los hechos victimizantes en el Naya. Esta es una percepción de "injusticia" porque el seguimiento a las audiencias permite inferir que sí se han dado capturas e investigaciones según lo dicho por los paramilitares: las investigaciones adelantadas en la actualidad por las Fiscalías 18 y 40 de Justicia y Paz contra los militares capitán (r) Mauricio Zambrano Castro, coronel (r) Tony Alberto Vega y general (r) Francisco José Pedraza están fundamentadas en las declaraciones de Éver Veloza García y Armando Lugo, alias El Cabezón $n^{117}$.

Ahora bien, en una discusión más amplia cabe preguntar: ¿cuáles han sido los impactos políticos y sociales de los testimonios confesionales de los antiguos integrantes del bloque Calima de las AUC? ¿Cuál ha sido el debate y la discusión que las confesiones han propiciado? ¿Ha sido posible ese debate? ¿Qué incidencias ha tenido el protocolo judicial de restringir la difusión de los testimonios confesionales para garantizar el principio procesal de la reserva sumarial?

117 Este último es un caso interesante que demuestra que sus testimonios son objeto de extorsión económica para algunos políticos del Valle del Cauca (Luis Fernando Velasco y Dilian Francisca Toro). Ante la negativa de pagar la extorsión, Lugo amenazó a los políticos con involucrarlos con las actuaciones del bloque Calima. Cabe recordar que en la actualidad la Corte Suprema de Justicia ha condenado a sesenta dirigentes políticos colombianos, precisamente por sus relaciones con el paramilitarismo. 
A mi modo de ver, en Colombia, la discusión en torno a Justicia y Paz como propuesta transicional ha tomado caminos que resultan poco fructíferos. A pesar de los vacíos que la norma pueda tener, el principal problema está en unos lugares de enunciación que, parafraseando a Payne (2009), se ubican en orillas opuestas. En una vereda están los que desconfían de todo lo que puedan decir los perpetradores y algunos hombres públicos asociados a algunos grupos armados —un ejemplo de ello es lo que representa la figura del expresidente Álvaro Uribe Vélez, leído por un sector de la sociedad como uno de los promotores del paramilitarismo en Colombia en su historia reciente, pero también leído por otro sector como el salvador que logró frenar la insurgencia y desmovilizar el paramilitarismo a través de su política de seguridad democrática. Esta postura quisiera silenciar a los perpetradores que solo buscan justificar sus crímenes, por lo que se termina desconociendo lo que se diga, no se diga o se pueda llegar a decir. En la otra vereda están los que defienden el modelo de confesión, argumentando que las versiones libres de los perpetradores han dado resultados útiles, como la confesión de más de 25 mil homicidios, más de mil masacres, más de 13 mil expedientes enviados a la justicia ordinaria para que sean investigados, entre otros, miembros de la fuerza pública, funcionarios y dirigentes políticos por sus vinculaciones con los hechos confesados. Lo que media entre unos y otros son, en la mayoría de las veces, posturas discursivas moralizantes que culminan en la simple pero devastadora descalificación. Lo más claro que se percibe en esa discusión son las cifras que se obtienen de los procesos judiciales que Justicia y Paz adelanta; cifras siempre impactantes y, por lo mismo, siempre atractivas para unos discursos periodísticos que reducen la "violencia" a causa-efecto del conflicto armado, política y social expresada en el número de asesinados, desplazados, torturados y agredidos en sus derechos.

La reflexión, como también lo indica Payne (2009), no debería pasar por lo que dicen, dejen de decir, revelen, silencien u olviden los perpetradores. Sus relatos confesionales serán siempre libretos que no escapan a sus intereses. La reflexión debería pasar por los debates y las discusiones que en torno a las confesiones se tendrían que propiciar en el ámbito público. La reflexión tendría que pasar por lo que esas 
confesiones comunican literalmente, entendiendo que lo que comunican no es un asunto común para toda la sociedad. Y, precisamente, por no ser un asunto común a todos, el debate es importante, teniendo como base lo que dicen los perpetradores en Justicia y Paz.

En ese ejercicio de coexistencia contenciosa, Payne, siguiendo a Vivian Patraka, distingue entre el escenario-lugar de representación y el espacio de representación. Los escenarios o lugares de representación también moldean el tipo de confesión que los perpetradores producen, de tal suerte que es factible que los perpetradores nieguen, guarden silencio o aleguen amnesia en un estrado judicial a la espera de evitar un veredicto de culpabilidad por una corte. Esto fue lo que ocurrió con los hombres del bloque Calima en el proceso desarrollado por la justicia ordinaria, mientras en un escenario de acuerdo y negociación como es Justicia y Paz, se promueve otro tipo de testimonios confesionales en lo que surge el arrepentimiento y la delación. En los casos en que las confesiones se realizan para un escenario mediático, resaltan las versiones heroicas, sádicas o exageradas. Por el contrario, en el espacio de representación los sentidos y las interpretaciones que se desprenden del testimonio confesional son múltiples (Edelman, citado en Payne, 2009, p. 22) y, por esa característica, los significados del pasado se controvierten y se rehacen (Auslander, citado en Payne, 2009 , p. 23). El espacio de representación propicia la participación de otros actores políticos: los medios de comunicación, las víctimas, los sobrevivientes, las organizaciones de derechos humanos, que se apropian del espacio de representación para discutir, interpelar o subvertir lo que está ocurriendo. En las audiencias relacionadas con la masacre del Naya, los sobrevivientes y las víctimas cargan siempre piezas comunicativas, usualmente audiovisuales, para solicitar al magistrado o al juez presentarlas cuando no están de acuerdo con lo que los perpetradores han dicho. En otros procesos de Justicia y Paz, incluso, los asistentes no han dudado en interrumpir las audiencias para interpelar las versiones de los perpetradores, acompañando sus voces con carteles con diversas consignas de rechazo. En un horizonte más amplio, ese espacio de representación tiene en los medios de comunicación un actor clave, por su poder político. Los asistentes a las audiencias de Justicia y Paz son pocos, la mayoría son personas con algún interés 
particular, lo que implica que en el espectro social los testimonios y las confesiones que circulan se conozcan a través de los medios. Esos testimonios mediatizados, en los que subyacen procesos de edición y selección del material registrado, se convierten en un hecho confesional no en su interpretación. La consigna, entonces, es que las representaciones mediáticas se convierten en espacios a través de los cuales el público discute el sentido político de las confesiones de los perpetradores respecto a las violencias del pasado, incluso cuando hay afirmaciones que, de algún modo, pueden ser refutadas. En ese contexto, los medios de comunicación son escenarios clave en marcos transicionales que suelen soslayar el rol que pueden desempeñar (Payne, 2009, p. 23).

En Colombia, no obstante, los medios de comunicación aún no son los espacios de representación que permiten un ejercicio de coexistencia contenciosa porque los temas de Justicia y Paz no son trascendentes para unas agendas informativas que, en el mejor de los casos, abordan el asunto según los registros que he denominado farmacéuticos, pues venden literalmente la ilusión de "informar" cuando presentan una noticia relacionada con el tema. Quiero ejemplificar el argumento con dos situaciones recientes.

A finales de 2012 dos noticias se produjeron en relación con Justicia y Paz. La primera estuvo fechada el 12 de diciembre cuando los magistrados de la Sala de Justicia y Paz del Tribunal Superior de Bogotá celebraron la legalización de cargos contra Éver Veloza García, alias $\mathrm{HH}$, en calidad de comandante de los bloques Bananero y Calima de las Autodefensas Unidas de Colombia. En total se registraron 88 crímenes entre masacres, homicidios, concierto para delinquir, torturas, secuestro, reclutamiento de menores de edad, entre los delitos más resonantes. Y aunque muchos de ellos estaban relacionados con la masacre del Alto Naya, más impactante aún fue la declaración de los magistrados respecto a considerar de manera oficial, por primera vez en la historia reciente del país, como un genocidio político el exterminio de más de dos mil miembros de la Unión Patriótica (UP) ${ }^{118}$.

118 La Unión Patriótica (UP) es un partido político de izquierda, cuya formación se remonta al proceso de negociación que las Farc-EP adelantaron con el gobierno del entonces presidente Belisario Betancourt Cuartas (1982-1986). 
La segunda noticia se produjo un par de días después, el 17 de diciembre, cuando en la misma Sala se condenó a ocho años de prisión (la pena máxima prevista por la norma) a uno de los comandantes más importantes de las Autodefensas Unidas de Colombia que no fue extraditado a los Estados Unidos ${ }^{119}$; se trata de Fredy Rendón Herrera, alias El Alemán, que comandó el emblemático bloque Elmer Cárdenas que operaba en la región Pacífica, especialmente en el departamento del Chocó. En desarrollo de la audiencia condenatoria, la Fiscalía hizo una solicitud trascendente en el ámbito jurídico, social y político, pero intrascendente para el registro periodístico: investigar y perseguir los bienes de las sucursales en Colombia de la transnacional Chiquita Brands, con el propósito de reparar a las víctimas de la región del Urabá antioqueño y chocoano, ubicado en la parte noroccidental del país, dada la responsabilidad de la corporación en la financiación del paramilitarismo durante los años noventa ${ }^{120}$. Lo cierto es que ambos acontecimientos, relevantes en el "marco transicional", pasaron inadvertidos, agotados en noticias de un par de segundos ${ }^{121}$. Solo el portal digital

Dos candidatos presidenciales (Jaime Pardo Leal y Bernardo Jaramillo Ossa), ocho congresistas, trece diputados, setenta concejales, once alcaldes y más de cinco mil militantes fueron sistemáticamente asesinados en un lapso de poco más de cinco años, en una estrategia de exterminio que involucró a grupos paramilitares, fuerzas de seguridad del Estado y narcotraficantes. Una reconstrucción de la historia de exterminio del movimiento político aparece en el documental El baile rojo (2003) del director Yesid Campos.

119 Cabe recordar que, entre 2008 y 2009, catorce comandantes y perpetradores de los grupos paramilitares fueron extraditados a Estados Unidos, requeridos por cargos relacionados con lavado de activos.

120 Chiquita Brands, empresa sucesora de la otrora United Fruit Company, fue investigada en 2007 por el Departamento de Justicia de los Estados Unidos por su comprobada financiación a grupos paramilitares en Colombia por un valor estimado de 1.7 millones de dólares. La compañía admitió ante un tribunal federal que efectivamente financió a los paramilitares a cambio de recibir protección para sus empleados. La empresa fue multada por 25 millones de dólares. La corte federal ha mantenido en reserva los documentos y los nombre de los ejecutivos que autorizaron los pagos (Evans, 2007).

121 También pasó inadvertido por los medios colombianos el informe de la Corte Penal Internacional que, en noviembre de 2012, señaló que el caso de los mal llamados falsos positivos (asesinatos sumarios perpetrados por miembros 
Verdadabierta.com cubrió la noticia, y analizó lo que ambas decisiones judiciales implican.

A la ausencia de un interés de los medios periodísticos colombianos por trascender el simple registro de los eventos que se suscitan en Justicia y Paz, cabe agregar una decisión que resulta problemática para propiciar una discusión pública amplia sobre el fenómeno paramilitar en la historia reciente de Colombia: la limitación de la publicidad de las versiones libres de los perpetradores, que reduce el eventual impacto democrático que las confesiones pueden tener en la opinión pública. Esa limitación está dada por dos vías: la primera corresponde a la tecnología propia de Justicia y Paz, basada en el principio procesal que garantiza el debido proceso de los imputados y la reserva sumarial de las diligencias ${ }^{122}$. Por extensión, la segunda vía se materializa en la ausencia de una política o, por lo menos, de una directriz institucional que permita que parte de los juicios sean públicos. El resultado es la imposibilidad de que la sociedad pueda reflexionar y rechazar moralmente lo que ha significado el fenómeno paramilitar (con sus particulares prácticas que degradan la condición humana) y, en un horizonte más amplio, más de seis décadas de una guerra que para la mayoría sigue siendo ininteligible.

de la fuerza pública y cuyas víctimas fueron jóvenes de los sectores populares de las principales ciudades del país) se puede considerar que la práctica formó parte de una política de Estado. El informe indica que: "There is a reasonable basis to believe that the acts described above were committed pursuant to a policy adopted at least at the level of certain brigades within the armed forces, constituting the existence of a State or organizational policy to commit such crimes" (CPI, 2012, p. 3).

$122 \mathrm{El}$ asunto quedó resuelto jurídicamente a través de la Sentencia T-049 (2008) proferida por la Corte Constitucional, que determinó los alcances y limitaciones en torno al principio de publicidad de las actuaciones judiciales de los postulados a Justicia y Paz. La sentencia establece que la etapa de investigación es reservada a la comunidad, pero no para las víctimas "quienes pueden conocer las diligencias dirigidas a indagar sobre la verdad de lo sucedido para hacer eficaz la justicia del Estado". 